Provided for non-commercial research and education use. Not for reproduction, distribution or commercial use.

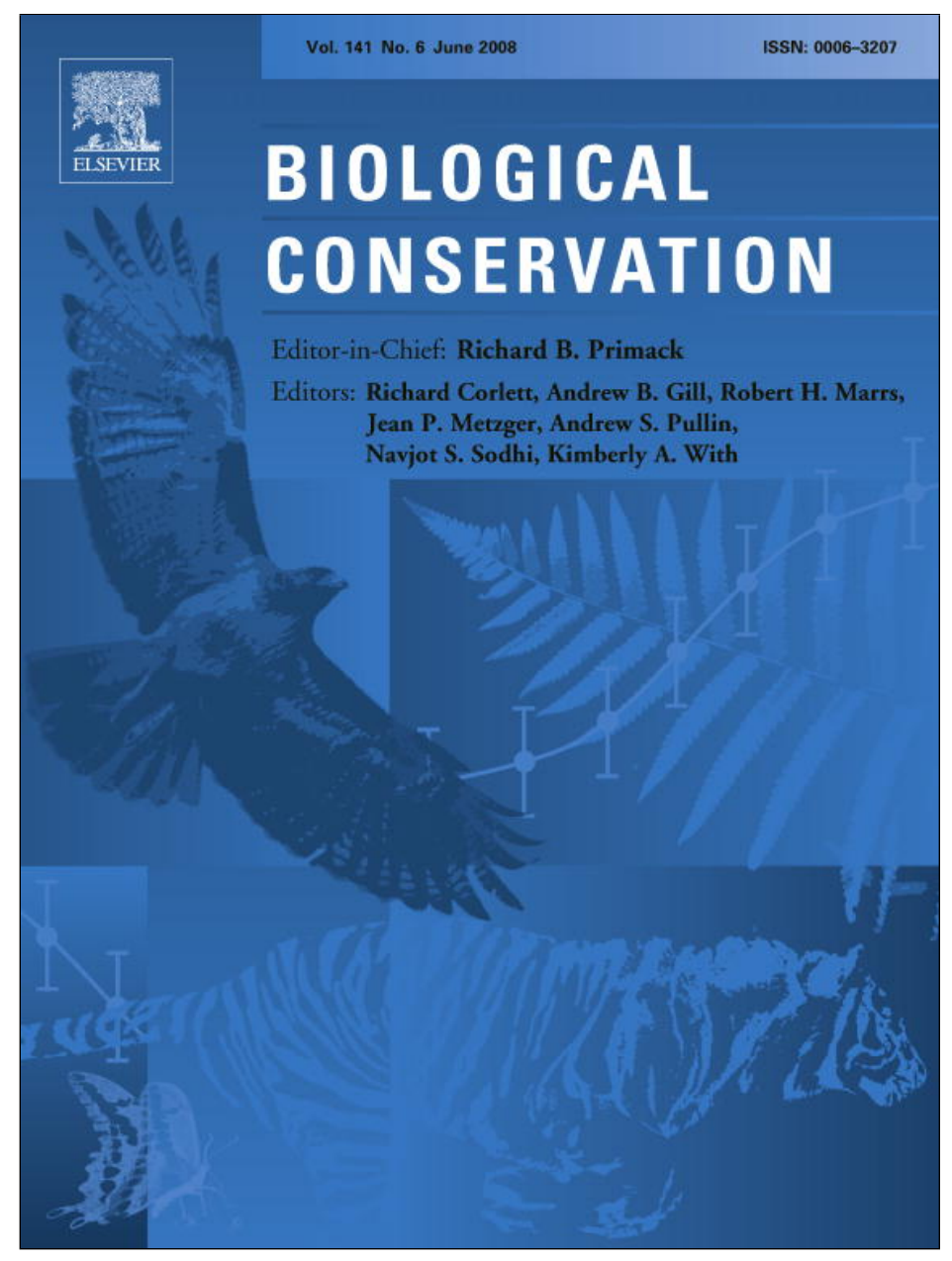

This article appeared in a journal published by Elsevier. The attached copy is furnished to the author for internal non-commercial research and education use, including for instruction at the authors institution and sharing with colleagues.

Other uses, including reproduction and distribution, or selling or licensing copies, or posting to personal, institutional or third party websites are prohibited.

In most cases authors are permitted to post their version of the article (e.g. in Word or Tex form) to their personal website or institutional repository. Authors requiring further information regarding Elsevier's archiving and manuscript policies are encouraged to visit:

http://www.elsevier.com/copyright 


\title{
Reproductive biology and ecology of selected rare and endangered Oxalis L. (Oxalidaceae) plant species
}

\author{
Johlene Zietsman ${ }^{a}$, Léanne L. Dreyer ${ }^{a, *}$, Karen J. Esler ${ }^{b}$ \\ ${ }^{a}$ Department of Botany and Zoology, University of Stellenbosch, Private Bag X1, Matieland 7602, South Africa \\ ${ }^{\mathrm{b}}$ DST-NRF, Department of Conservation Ecology and Entomology and Centre for Invasion Biology, University of Stellenbosch, Private Bag X1, \\ Matieland 7602, South Africa
}

\section{A R T I C L E I N F O}

\section{Article history:}

Received 24 August 2007

Received in revised form

17 March 2008

Accepted 19 March 2008

Available online 23 May 2008

\section{Keywords:}

Habitat specificity

Rarity

Small population size

Tristyly

\begin{abstract}
A B S T R A C T
About twenty-five percent of all southern African Oxalis species are rare/endangered and highly localized, making them especially vulnerable to extinction through inbreeding, low genetic variation, disrupted biological interactions and stochastic events; all consequences of small population sizes. Moreover, Oxalis displays tristyly, which is a rare and specialized sexual system that includes a strong self-incompatibility component between three floral morphs to promote out-crossing within populations. As tristyly requires the availability of plants with different floral morphs as well as effective pollinators for seed production, this breeding system can affect small populations when fully expressed. Factors that may have an effect on rarity in Oxalis were investigated by focusing on the expression of tristyly, levels of natural seed production, clonality and the ecology of eight rare/highly localized Oxalis species. Field experiments revealed that the reproductive success of some Oxalis species may be hampered by tristyly, resulting in extremely low levels of natural seed production. Other species display a more relaxed expression of self-incompatibility, which in combination with the possibility of cross-pollinations provides reproductive assurance regardless of population structure and pollinator availability. Others are rare and endangered, but appear not to be negatively affected by the tristylous breeding system. Most species are limited by their highly specific habitat requirements and are particularly vulnerable to variation in rainfall patterns.
\end{abstract}

(c) 2008 Elsevier Ltd. All rights reserved.

\section{Introduction}

The South African flora includes 3268 known threatened plants species, which, given the area of the country, means that South Africa has the highest concentration of threatened plant taxa in the world. Most threatened taxa are found in the Cape Floristic Region (CFR) (Hilton-Taylor, 1996), an area listed as one of 25 global biodiversity hotspots (Myers et al., 2000). The genus Oxalis (Oxalidaceae) displays two global centres of diversity, one in South-Central America (Lourteig, 1994, 1995, 2000) and another in southern Africa (Salter, 1944).
Within southern Africa, Oxalis represents the seventh largest genus in the CFR (Goldblatt and Manning, 2000), but an estimated 53 of the 210 southern African Oxalis species are rare or endangered and very locally distributed (Hilton-Taylor, 1996).

Rare species can be defined as species with narrow geographical distribution ranges, highly specific habitat requirements and/or species restricted only to small populations (Primack, 1993, 2002). Factors that cause rarity, and the consequences thereof, are fundamental issues in ecology and conservation biology (Jankowski and Rabenold, 2007). Small

\footnotetext{
* Corresponding author: Tel.: +27 21 8083070; fax: +27 218082405.

E-mail addresses: ziets@sun.ac.za (J. Zietsman), ld@sun.ac.za (L.L. Dreyer), kje@sun.ac.za (K.J. Esler). 0006-3207/\$ - see front matter ( 2008 Elsevier Ltd. All rights reserved. doi:10.1016/j.biocon.2008.03.017
} 
populations are particularly vulnerable to extinction due to vulnerability to environmental stochasticity, low genetic variability caused by genetic drift and inbreeding depression that may reduce individual fitness (Primack, 1993, 2002). Furthermore, small, isolated populations often suffer from disrupted biological interactions (Luijten et al., 2000; Hooftman et al., 2003). These effects are likely to be more severe for species with complex breeding systems containing strong selfincompatibility and a limited number of mating types (Brys et al., 2004). Morph anisoplethy, together with reduced pollinator activity, may reduce mating opportunities in small populations that are completely dependant on pollination between different morph types (Byers and Meagher, 1992; Brys et al., 2004).

About $25 \%$ of southern Africa Oxalis species are considered rare (Hilton-Taylor, 1996). In addition, all southern African members of Oxalis are tristylous (Salter, 1944), a form of heterostyly that includes three different morph types (long, mid and short, according to stigma height) within a population. Reproductive organs are reciprocally arranged such that each morph type produces flowers with two anther levels that correspond to the stigma levels in the remaining two morphs. This morphological trimorphism, together with a strong selfincompatibility component, enforces out-crossing in that seed production is limited to legitimate crosses (between stigmas and anthers of equivalent heights) only. Enforced outcrossing should reduce the negative effects of close inbreeding in plant populations (Ornduff, 1964; Weller, 1992). Genetic control via a two-locus system ensures a 1:1:1 ratio of the floral morphs in large populations at the isoplethic equilibrium (Barrett, 1992; Richards and Barrett, 1992). Tristyly requires equal availability of morph types and an effective pollen vector to function affectively. It could therefore be restrictive to sexual reproduction in small populations in which these requirements are often not met (Brys et al., 2004). Several studies have shown modifications to one or more of the components of tristyly (Ornduff, 1972; Barrett, 1979; Charlesworth, 1979; Weller, 1976, 1992; Graham and Barrett, 2004). As a result, a relaxed self-incompatibility could provide reproductive assurance regardless of pollinator and mate availability, thus enabling at least the short term survival of rare populations. In addition to sexual reproduction, all southern African Oxalis species also reproduce vegetatively through the productions of bulbils from an underground rhizome (Ornduff, 1974; Salter, 1944), which may counter unsuitable conditions for seed production and/or seedling establishment.

The aim of this study was to assess factors that may influence rarity in selected southern African Oxalis species by considering the (I) reproductive biology and (II) ecological preferences of selected species in the Western Cape Province, South Africa. The first objective was to determine to what extent the reproductive success of selected rare/endangered Oxalis species are affected (positively or negatively) by their reproductive biology by assessing the tristyly expression, natural seed production and levels of vegetative reproduction (clonal growth). The breakdown of one or more components of the tristylous breeding system may significantly alter the reproductive assurance and thus survival of a species. Three aspects of tristyly, self-incompatibility, population structure (morph ratios) and flower morph morphology were assessed. Levels of natural seed production (seed production in the wild) were also explored to determine if sexual reproduction is restricted within rare populations. Low seed production could result from unequal morph availability, absence of pollinators and/ or lower fecundity as a consequence of inbreeding depression in small populations. (Hooftman et al., 2003). The extent of clonality was assessed to determine to what extent vegetative propagation could counter sexual reproductive bottlenecks. In the long run, however, very high levels of clonality only would lead to reduced genetic diversity (Burne et al., 2003).

A second objective was to determine the most likely ecological threats to the survival of the rare/endangered species O. amblyosepala, O. comptonii, O. giftbergensis, O. hygrophila, O. natans, O. oculifera, O. oligophylla and O. oreophila. Abiotic and biotic features (habitat type, specificity and availability, population size and density, climate data and potential threats) of each species were explored and related to their reproductive status.

\section{Materials and methods}

\subsection{Study species}

Rare species were selected from across the phylogeny of southern African Oxalis species to be as phylogenetically representative as possible (Oberlander et al., 2004; Oberlander pers. com.). With the exception of $O$. hygrophila and O. oligophyla that form a well-supported monophyletic clade along with the widespread species $\mathrm{O}$. tomentosa $\mathrm{L}$., all the other rare species included in this study resolve to separate, well-supported sub-clades within the Oxalis phylogeny (Oberlander, pers com.). Five of the rare/endangered species (Table 1) are endemic to the Giftberg Mountain (Vanrhynsdorp): Oxalis amblyosepala, O. comptonii, O. giftbergensis, O. oculifera and O. oligophylla. Two further species, O. hygrophila and O. oreophila, are restricted to the Pakhuis Pass Mountain (Clanwilliam). Most of these rare species are restricted to single populations, so that only one population could be studied per species. Populations of Oxalis amblyosepal$a$ and $O$. oculifera consist of a network of small isolated patches (forming a single meta-population) restricted to the Giftberg Mountain only. We considered these species still to represent a single population, but data were collected from meta-populations across the entire population. Oxalis natans is an aquatic species restricted to remnants of vernal pools (seasonally

\begin{tabular}{lccc}
\multicolumn{4}{l}{$\begin{array}{l}\text { Table 1 - Distribution, flowering period and study site of } \\
\text { the South African Oxalis species that were compared in } \\
\text { terms of reproductive biological and ecological attributes }\end{array}$} \\
\hline Species & $\begin{array}{l}\text { Flowering } \\
\text { period }\end{array}$ & Study site & Distribution \\
\hline O. amblyosepala & May-July & Giftberg & Localised \\
O. comptonii & May-June & Giftberg & Localised \\
$\begin{array}{l}\text { O. giftbergensis } \\
\text { O. hygrophila }\end{array}$ & May-June & Giftberg & Localised \\
O. natans & September & Pakhuis Pass & Localised \\
& November & 2. Stellenbosch & Localised \\
O. oculifera & May-June & Giftberg & Localised \\
O. oligophylla & May-June & Giftberg & Localised \\
O. oreophila & May & Pakhuis Pass & Localised \\
\hline
\end{tabular}




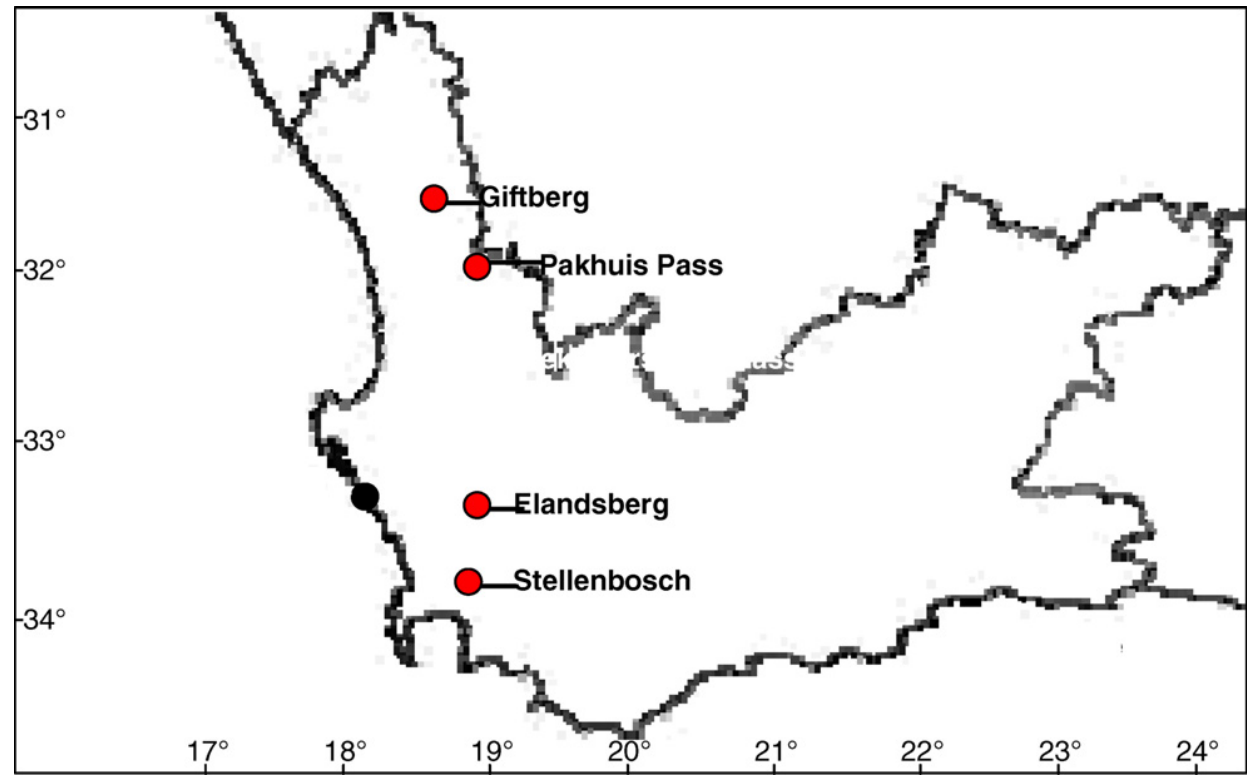

Fig. 1 - Geographic locality of the sites in the Western Cape (South Africa) at which the different rare Oxalis species were studied.

aquatic habitats) in the Western Cape. We studied one highly disturbed population (Stellenbosch) and one natural population (Elandsberg) of this species (Table 1). The geographic localities of the species included in this study are depicted in Fig. 1.

\subsection{Reproductive biology}

We studied the reproductive biology of all populations of all species, except $O$. hygrophila for which no flowering material was available. The limited number of flowering plants and the short flowering period of 0 . oligophylla resulted in some crossing-experiments (assessments of self-incompatibility expression and natural seed production) not being performed.

\subsubsection{Tristyly expression}

We conducted field-based artificial pollinations to assess the expression of self-incompatibility in the selected species. Seed production following controlled self-pollinations was compared to seed production following legitimate cross-pollinations (control), where seed production is expected to be at a maximum. Ten replicates of each cross-combination (Table 2) were performed randomly in the field.

We emasculated flowers on the first day of anthesis, after which pollen from the desired anther whorl was rubbed onto

Table 2 - The pollination types performed represented as selected stylar morph (i) $\times$ specific anther level/style-morph (o')

\begin{tabular}{llll} 
Selfing & & \multicolumn{2}{c}{ Legitimate crosses } \\
\hline $\mathrm{L} \times \mathrm{s} / \mathrm{L}$ & $\mathrm{L} \times \mathrm{m} / \mathrm{L}$ & $\mathrm{L} \times \mathrm{l} / \mathrm{S}$ & $\mathrm{L} \times \mathrm{l} / \mathrm{M}$ \\
$\mathrm{M} \times \mathrm{s} / \mathrm{M}$ & $\mathrm{M} \times \mathrm{l} / \mathrm{M}$ & $\mathrm{M} \times \mathrm{m} / \mathrm{S}$ & $\mathrm{M} \times \mathrm{m} / \mathrm{L}$ \\
$\mathrm{S} \times \mathrm{m} / \mathrm{S}$ & $\mathrm{S} \times \mathrm{l} / \mathrm{S}$ & $\mathrm{S} \times \mathrm{s} / \mathrm{M}$ & $\mathrm{S} \times \mathrm{s} / \mathrm{L}$ \\
\hline $\begin{array}{l}\mathrm{L}, \mathrm{M} \text { and S represent stylar morphs and } \mathrm{s}, \mathrm{m} \text { and l represent anther } \\
\text { levels. }\end{array}$ & & \\
\hline
\end{tabular}

the stigma using fine forceps. Artificially pollinated flowers were bagged to avoid uncontrolled pollination. After collecting mature fruits the percentages of flowers that produced seed for each of the different floral morphs per pollination treatment were determined. The index of self-incompatibility (ISI) was expressed as the ratio of the number of fruits formed following manual self-pollination relative to the number formed following manual cross-pollination, following Zapata and Arroyo (1978).

Data from experimental pollinations were analyzed by nonparametric statistics (Statistica software package, version 7) as many flowers did not set fruit, causing this variable to be nonnormally distributed. Mann-Whitney U-tests were performed to compare selfing to legitimate cross-pollinations and to compare natural seed production to legitimate cross-pollinations. Kruskal-Wallis ANOVA $H$ was used to test for differences between the three floral morphs for all pollination types.

We examined population structures by determining the flower morph frequency in each population. We recorded the floral morph of at least 100 flowers (where possible) per population during peak flowering. Plants were sampled at $1-2-m$ intervals to avoid the sampling of clones. Morph frequencies were analyzed by $G$ statistics (Sokal and Rohlf, 1995) for goodness-of-fit to an expected isoplethic (1:1:1) equilibrium. We measured the reproductive organs of 20 randomly chosen flowers of each morph type to assess morph morphology. Stigma and anther heights were measured from the base of the ovary using calipers. Organ heights of individuals were plotted to compare morphological alterations of tristyly in different populations and species.

\subsubsection{Natural seed production}

We bagged 25 randomly chosen flowers of each morph type in the wild after allowing sufficient time for natural pollination to have occurred (when petals start to dehisce). Seed production in these untreated (open pollinated) flowers was 
compared to seed production following artificial legitimate cross-pollination where seed production is expected to be at a maximum.

\subsubsection{Vegetative reproduction}

We studied the extent of clonality by quantifying bulbil formation on living material and available herbarium specimens obtained from the Stellenbosch University Herbarium (STEU). In addition, we analyzed the transition of floral morphs along transects, where 50 nearest-neighbour individuals per population were sampled. We assumed that a high transition of morphs would indicate low levels of clonality, as vegetative reproduction produces plants of the same morph type growing in close proximity to one another. The frequencies of two neighbours being of the same floral morph vs. two neighbours being of different floral morphs were analyzed. We used $G$ statistics (Sokal and Rohlf, 1995) to determine to what extent the ratio of the frequencies of two neighbours being of the same floral morph vs. two neighbours being of different floral morphs deviates from 1:1. A ratio of 1:1 should indicate moderate levels of clonality, while a significant deviation towards the frequency of two neighbours being of the same morph type should indicate high levels of clonality. A significant deviation toward the frequency of two neighbours being of different floral morphs should indicate extremely low levels of clonality.

\subsection{Ecology}

We determined the geographical distribution of each species using locality data obtained from the Compton (NBG) and Bolus (BOL) Herbaria and the Pretoria Computerized Information System (PRECIS) database. During population surveys we evaluated each species for preferred habitat type, habitat specificity and availability. The following habitat attributes were considered: (1) vegetation type; (2) substrate; (3) moisture regime; (4) soil type; (5) lithology; (6) exposure; (7) aspect; (8) slope. Population size and density as well as potential threats to specific populations were evaluated. In addition, we obtained current and longer-term rainfall data from weather stations nearest to the selected study sites and compared these to the current biological state of the populations.

\section{Results}

\subsection{Reproductive biology}

3.1.1. Expression of self-incompatibility and natural seed production

When tristyly is fully expressed self-pollinations should yield no seed, but this was only evident in $\mathrm{O}$. amblyosepala and $\mathrm{O}$. natans. Controlled self-pollination experiments (Table 3) indicate varying degrees of self-compatibility in 0 . comptonii and O. oculifera. Seed production is expected to be at a maximum following legitimate pollination. In the rare species, legitimate seed production was low, but still much higher than seed production following self-pollination (Table 3).

Combined results of the three morph types revealed that total seed production following selfing was significantly lower than seed production following legitimate cross-pollinations

\begin{tabular}{|c|c|c|c|c|}
\hline \multirow{2}{*}{$\begin{array}{l}\text { Species } \\
\text { (population) }\end{array}$} & \multicolumn{3}{|c|}{ Total \% capsules } & \multirow[t]{2}{*}{ ISI } \\
\hline & Selfing & Legitimate crosses & Natural & \\
\hline O. amblyosepala & 0 & 58.3 & 32.9 & 0.00 \\
\hline O. comptonii & 11.7 & 53.3 & 65.3 & 0.22 \\
\hline O. giftbergensis & 1.7 & 53.3 & 65.3 & 0.03 \\
\hline O. natans (1) & 0 & 5 & 5.3 & 0.00 \\
\hline O. natans (2) & 0 & 61.7 & 50 & 0.00 \\
\hline O. oculifera & 11.7 & 68.3 & 58.7 & 0.17 \\
\hline O. oreophila & 3.3 & 71.7 & 78.7 & 0.05 \\
\hline
\end{tabular}

Seed production in naturally pollinated flowers and the self-incompatibility (ISI) index are also given.

as is expected in tristylous populations. O. natans 1 (Stellenbosch) was the only exception (Mann-Whitney U-test, adjusted $Z$ value 1.74679, $p=0.08067$ ), in that both legitimate pollinations and selfing resulted in a very low percentage seed production (Table 3). Only O. comptonii and O. oculifera displayed significant differences in self-compatibility between the three morph types and appeared to be highly self-compatible for the L morph (Kruskal-Wallis ANOVA, $\mathrm{H}=6.043127, p<0.05 ; \mathrm{H}=$ $6.043127, p>0.05$, respectively). Although the total percentage seed production (all three morph types combined) was significantly lower than percentage seed production following legitimate cross pollinations, the difference between these two pollination treatments was not significant when only the $\mathrm{L}$ morph of $O$. comptonii was considered (Mann-Whitney U-test, adjusted $Z$ value $-0.978076, p=0.328037$ ). The importance of self-compatibility in this population is further supported by the index of self-incompatibility (ISI) of 0.26 , which is larger than the arbitrary proposed number of 0.20 required to characterize the population as partially self-compatible (Table 3 ).

The levels of natural seed production varied between the different populations studied (Table 3). Natural seed production was especially low in the completely self-incompatible O. amblyosepala and O. natans (1). Regardless of the low observed levels of natural seed production in many populations, only O. amblyosepala revealed significantly lower levels of natural seed production compared to seed production following legitimate cross-pollinations (Mann-Whitney U-test, O. amblyosepala, adjusted $Z$ value $2.955254, p<0.05$ ). For $O$. natans (1) both natural seed production and seed production following legitimate pollinations were extremely low. There were no significant differences in seed production of different morph types for either legitimate cross-pollinations or natural seed production in the wild for any of the populations studied.

\subsubsection{Morph frequencies}

$O$. comptonii and $O$. oculifera were the only rare species that displayed significant deviations from the expected 1:1:1 (isoplethic equilibrium) morph frequency (Table 4).

\subsubsection{Morph morphology}

Plots of organ heights with individuals arranged in decreasing stigma height for each morph show considerable variation among individuals of the same morph (Fig. 2). Gaps in the 
Table 4 - Floral morph frequencies for Oxalis populations compared by a $\mathrm{G}$ test for goodness-of-fit to an isoplethic (1:1:1) equilibrium

\begin{tabular}{|c|c|c|c|c|c|}
\hline \multirow[t]{2}{*}{ Species } & \multirow[t]{2}{*}{$n$} & \multicolumn{3}{|c|}{ Floral morph } & \multirow[t]{2}{*}{ Significance } \\
\hline & & $\mathrm{L}$ & $\mathrm{M}$ & G & \\
\hline O. amblyosepala & 105 & 33 & 37 & 0.229 & NS \\
\hline O. comptonii & 51 & 14 & 11 & 7.081 & $P<0.05$ \\
\hline O. giftbergensis & 104 & 33 & 40 & 1.265 & NS \\
\hline $\begin{array}{l}\text { O. natans (1) } \\
\text { (Stellenbosch) }\end{array}$ & 100 & 30 & 31 & 1.425 & NS \\
\hline $\begin{array}{l}\text { O. natans (2) } \\
\text { (Elandsberg) }\end{array}$ & 86 & 24 & 24 & 4.363 & NS \\
\hline O. oculifera & 109 & 28 & 51 & 8.505 & $P<0.05$ \\
\hline O. oligophylla & 56 & 12 & 26 & 5.317 & NS \\
\hline O. oreophila & 94 & 28 & 27 & 2.736 & NS \\
\hline
\end{tabular}

figures (O. comptonii and O. oligophylla, Fig. 2) indicate cases when less than 20 flowers were recorded for a particular morph type. Morphologically tristylous populations (O. ambly.
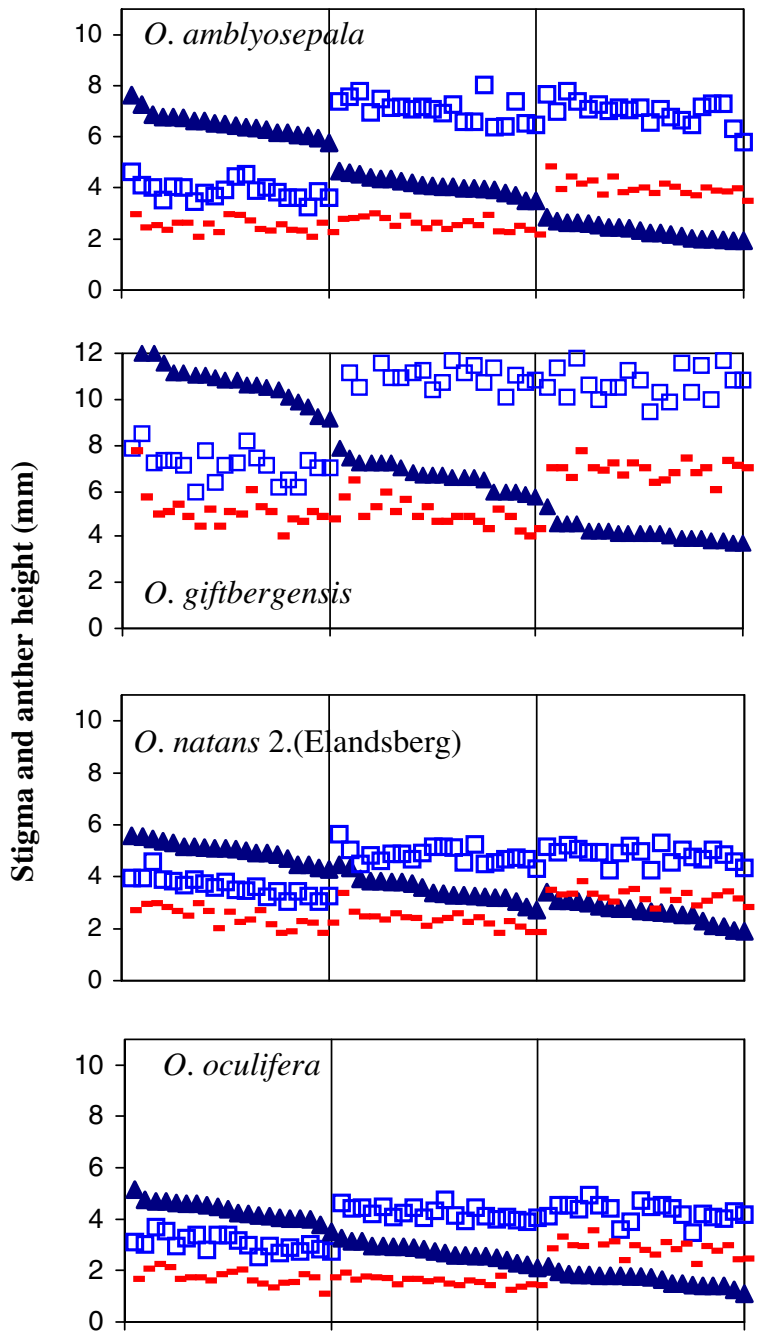

$\mathbf{L}$ osepala, O. giftbergensis and O. oreophila) show a clear discontinuity of stigma heights between the long and the mid, and the mid and short stigma heights and there are three clearly separated organ levels in each morph. A second trend shows a continuum of stigma heights between the different morphs (O. natans 1,0 . comptonii and 0 . oculifera), but three separated organ heights are still present within each morph type. Thirdly, there are populations in which the styles are not of three distinct lengths, and this is coupled with an overlap in organ heights in the different morph types (O. natans 2 and O. oligophylla). O. oculifera and O. natans have very small flowers and the separation between organ heights appears to be much less than in the other species studied.

\subsubsection{Vegetative reproduction}

Field surveys indicated that vegetative reproduction is not very pronounced among the rare species studied (Table 5). When frequencies of neighboring plants of similar morph type vs. plants of dissimilar morph types in transects of 50 individuals were compared to $1: 1, G$ statistics revealed no
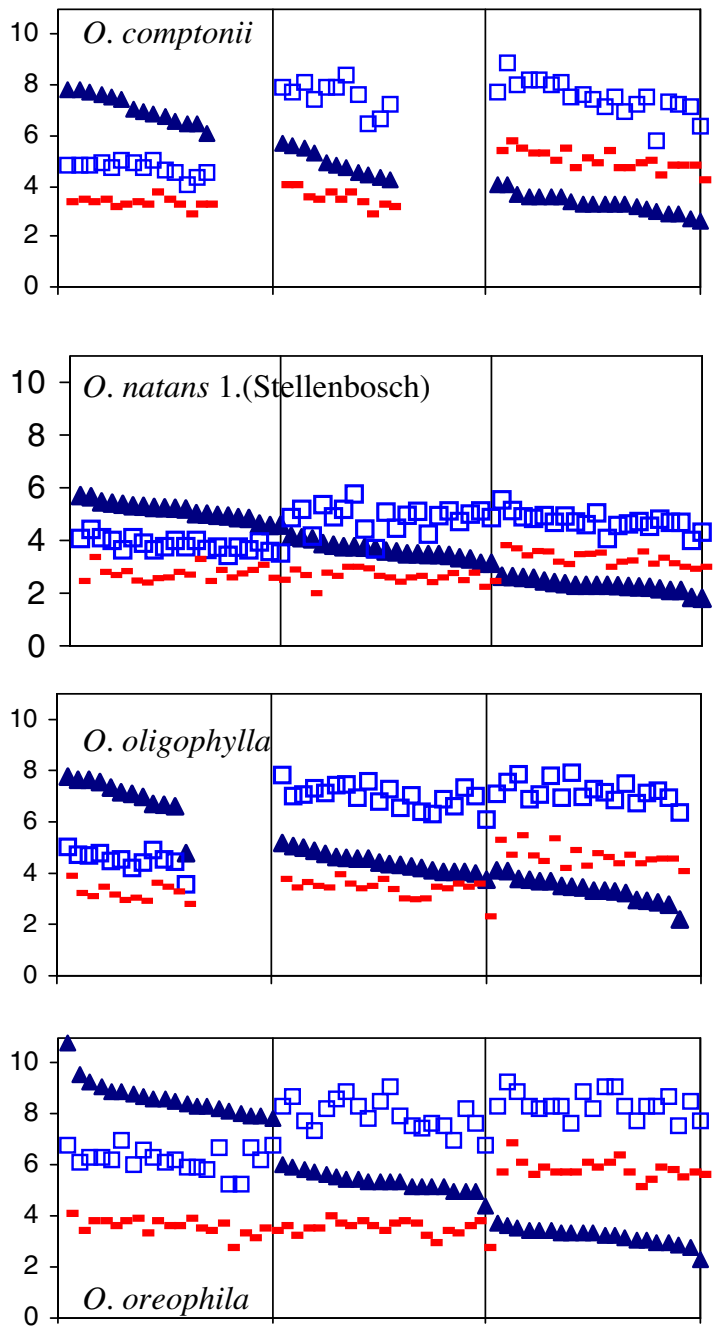

$\mathbf{L}$

M

$\mathbf{S}$

Fig. 2 - Variation in the heights of stigmas and anthers in populations of rare/endangered Oxalis species. Individuals in each population are ordered by decreasing style length (Style $\Lambda$, upper anthers $\square$, lower anthers $-; \mathrm{L}=$ long $\mathbf{m o r p h}, \mathbf{M}=\mathbf{m i d}$ morph, $\mathbf{S}=$ short morph). 
Table 5 - Frequencies of plants of similar morph type vs. plants of dissimilar morph types occurring next to each other along transects intersecting $\mathbf{5 0}$ individuals of each population

\begin{tabular}{|c|c|c|c|c|c|}
\hline \multirow[t]{2}{*}{ Species } & \multicolumn{2}{|c|}{ Frequency } & \multirow[t]{2}{*}{ G } & \multirow[t]{2}{*}{ Significance $^{a}$} & \multirow[t]{2}{*}{ Clonality } \\
\hline & $\begin{array}{l}\text { Similar morphs } \\
\text { next to each other }\end{array}$ & $\begin{array}{l}\text { Dissimilar morphs } \\
\text { next to each other }\end{array}$ & & & \\
\hline O. amblyosepela & 0.72 & 1.28 & 3.973 & NS & Moderate \\
\hline O. comptonii & 0.68 & 1.32 & 5.211 & NS & Moderate \\
\hline O. giftbergensis & 0.52 & 1.48 & 12.009 & $P<0.05$ & Low \\
\hline O. natans (1) & 1.52 & 0.48 & 14.207 & $P<0.05$ & High \\
\hline O. natans (2) & 1.28 & 0.72 & 3.973 & NS & Moderate \\
\hline O. oculifera & 0.88 & 1.12 & 0.722 & NS & Moderate \\
\hline O. oligophylla & 0.68 & 1.32 & 5.211 & NS & Moderate \\
\hline O. oreophila & 1.00 & 1.00 & 0.000 & NS & Moderate \\
\hline
\end{tabular}

significant deviation in most of the rare populations. This suggests moderate levels of clonality in the rare species. A strong deviation towards neighboring plants being of dissimilar morph types indicates low levels of clonal growth in $O$. giftbergensis. In contrast, one population of 0 . natans (1) showed a strong tendency for neighboring plants to be of the same morph type, suggesting high levels of clonality in the very disturbed $O$. natans population.

\subsection{Ecology}

O. amblyosepala, O. oculifera and O. comptonii are Giftberg endemics found in very specific, fragile habitats. O. amblyosepala is restricted to Restionaceae-dominated flat plains, where it occurs only in seasonally waterlogged soil pockets and between flat sandstone rocks. It forms small, locally dense patches (meta-populations) rich in mosses and lichens. Its flowering period extends from May to July. O. oculifera and O. comptonii co-occur in rather similar habitat to O. amblyosepala in the Giftberg. These seasonally waterlogged microhabitats comprise a lens of fine clay on a solid layer of sandstone bedrock and are associated with small streams that develop during the rainy winter months. Both species have a very high local density (especially O. oculifera), a flowering period from May to July and grow in patches with mosses, ferns, lichens and Drosera species.

The number and sizes of O. amblyosepala, O. comptonii and O. oculifera patches appear to be very dependent on rainfall, and varied considerably between 2005 and 2006. During the wetter 2006 (rainfall $158 \mathrm{~mm}$ ), many new population components were observed within meta-populations than during May-July 2005 (rainfall $104 \mathrm{~mm}$ ).

O. giftbergensis is restricted to refugia of arid fynbos on the Giftberg, where it is locally abundant in large populations. O. oligophylla, another Giftberg endemic, grows in low densities in rock crevices high on the Giftberg escarpment in Mountain Fynbos. Both O. giftbergensis and O. oligophylla flower from May to June.

O. hygrophila is known from a single locality on a moist, natural seepage band in the Pakhuis Pass. When visited in 2001 as in 1944 (when this population was first documented), flowers were present in November (Salter, 1944; Kumwenda et al., 2004). This late flowering time contrasts sharply with most other CFR Oxalis species, which have flowering peaks during the wetter winter months (May-July) (Dreyer et al., 2006). During 2005 and 2006, the type locality of this species was visited on several occasions during October-November, but no plant were found, and there was no evidence of water seepage down this slope. Visits earlier in winter, to detect possible earlier flowering, also revealed no plants. Total rainfall for both $2005(140 \mathrm{~mm})$ and $2006(190 \mathrm{~mm})$ was far below average for this region (average of $209 \mathrm{~mm}$ over 40 years) in contrast to 2001, during which the total rainfall was wellabove the average $(286 \mathrm{~mm})$. Both 2005 and 2006 experienced early winter rain that differed from the pattern experienced in 2001 when most of the winter rainfall was recorded much later in the season and closer to the flowering period of this species.

O. oreophila is restricted to grass and Restionaceae dominated water seepage bands in the Pakhuis Pass, and has a short flowering period during May. It occurs in an ecotone of renosterveld and fynbos on seasonally wet shale bands running down the slopes of these sandstone mountains.

O. natans, an aquatic with a long, slender, flexuous stems and shortly petiolate leaves that float on the water surface, has a restricted flowering period during September. The Stellenbosch population (O. natans 1 ) occurs in a heavily disturbed lowland renosterveld vlei (seasonal marshland). In this population, the small white flowers were confined to a stratum below the rest of the vegetation, while a different whiteflowered stratum (Onixotis, Ornithogalum and Spiloxene species) was also present ca. $30 \mathrm{~cm}$ above the flowers of 0 . natans. The Elandsberg Nature Reserve population (O. natans 2) also occurs in a vlei habitat (vernal pool), but here it occurs in natural renosterveld. It is a large, healthy population with $O$. natans as the dominant species. Flowers in this population are much more exposed and seemingly subjected to less pollinatorcompetition than O. natans (1).

\section{Discussion}

Rarity is controlled or caused by different factors in the different Oxalis species and is often the result of a combination of several factors. A distinction must be made between species 
that are intrinsically or naturally rare (Pärtel et al., 2005), and those that are rare or declining due to mostly human inflicted threats. If rarity is caused by population shrinkage and/or fragmentation, it can impact on the expression of tristyly and ultimately the reproductive success of such a species due to ecological and/or demographic issues. Reproductive and ecological results are thus discussed separately below. First we evaluate the impact of rarity on tristyly or vica versa, and then we collectively assess the ecological parameters affecting or controlling the rare species evaluated in this study.

\subsection{Reproductive biology}

\subsubsection{Tristyly expression}

Fully tristylous populations are expected to display complete self-incompatability and a morph frequency of 1:1:1 (isoplethic equilibrium). Such populations should also display three distinct morph morphological types. Deviations in tristyly expression may affect any one of these three attributes, resulting in self-compatibility and/or morph frequency shifts and/or a breakdown in morph morphology. The rare species studied here appear to vary in terms of tristyly expression, with some species displaying full tristyly expression, while others show deviations in terms of one or more components of tristyly.

O. amblyosepala, O. giftbergensis, O. natans and O. oreophila can be considered fully tristylous. The slight deviations in morph morphology in O. natans probably results from small flower size with reproductive organs borne very close together, while self-incompatibility is slightly leaky in O. giftbergensis and $\mathrm{O}$. oreophila. Such fully expressed tristylous systems may be restrictive to sexual reproduction in small, isolated populations if requirements of effective pollinator availability and equal morph availability are not met (Brys et al., 2004). This may be the case O. amblyosepala and O. natans (1). The completely self-incompatible O. amblyosepala population displays significantly lower seed production in the wild than seed production following artificial legitimate pollinations. This observed low sexual success does not result from unequal morph availability, as the population is at isoplethic equilibrium, so most probably results from reduced natural pollination success. It is well-known that small population sizes often lead to disrupted biological interactions (Luijten et al., 2000; Hooftman et al., 2003). Pollinator limitation may also limit seed production in the disturbed $O$. natans population (O. natans 1 ), where the flowers may not be visible or accessible to pollinators as they occur below an upper stratum of different while-flowered species.

The problems in the $O$. natans 1 population are more extensive though, since even artificial legitimate pollinations produced almost no seeds. This explains the lack of significant difference in seed production following selfing vs. legitimate cross-pollinations, which is mostly associated with highly self-compatible populations. This completely self-incompatible population, which appears to experience both pollinator stress and extremely low fecundity, therefore has to rely almost exclusively on vegetative reproduction for persistence. Burne et al. (2003) suggested that high levels of clonality, as demonstrated in this population, may be related to the loss of capacity to reproduce sexually.
In contrast, the reproductive success of 0 . giftbergensis, 0 . oreophila and 0 . natans (2) appears to unaffected by full tristyly expression and restrictive population sizes. O. natans (2) occurs in a natural habitat with no potentially pollination-inhibiting white-flowered stratum above the $O$. natans flowers. This completely self-incompatible population has much higher levels of both natural seed production (close to full potential) and seed production through controlled legitimate pollinations. O. giftbergensis and O. oreophila have slightly leaky self-incompatibility systems, which results in non-significant levels of seed production following self-pollination. The low ISI also shows that these two species cannot be considered partially self-compatible. Both species have high levels of natural seed production. Unlike in O. amblyosepala and O. natans (1), the intact tristylous breeding system does not appear to negatively impact on these three species (populations).

Deviations from full tristyly expression were observed in the rare species $O$. comptonii, $O$. oculifera and $O$. oligophylla. Both $O$. comptonii and $O$. oculifera produced very high percentages of seeds following self-pollinations, with the total ISI in O. comptonii high enough to view it as partially self-compatible. In both species, morph frequencies deviate significantly from 1:1:1 and both display variable morphological forms. Eckert and Barrett (1992) and Byers (1995) argued that morph frequencies often deviate from isoplethic equilibrium in small natural populations, and may result from genetic drift, founder effects or population bottlenecks. The non-isoplethic structure of such populations suggests natural seed production should be low due to unavailability of morph types (Byers, 1995). However, we observed no significant differences between natural seed production and seed production following controlled legitimate cross-pollinations in comptonii and $O$. oculifera. The ability to self-pollinate appears to benefit these species, as it enables seed production regardless of pollinator availability and/or the population structure. In these species, reproductive assurance may be more important than genetic variability attained by cross-pollination (Barrett, 1985). Despite their ability to self-pollinate, $O$. comptonii and $O$. oculifera have retained the potential to cross-pollinate, allowing genetic variability and fitness to increase through chance cross-pollinations. The O. oligophylla population has an extremely low density and displays moderate level of clonality. Although the population structure is healthy, various aberrant morph morphologies were observed. Plant density and out-crossing rates often correlate positively, as pollinators often spend more time per plant in populations with low densities (Franceschinelli and Bawa, 2000; Van Rossum et al., 2004). O. oligophylla, however, produces only 2-3 flowers/plant, so it may be argued that the low population density, along with only moderate levels of clonality, would enhance pollinator movements between morph types.

\subsubsection{Vegetative reproduction}

The onset and duration of flowering in southern African Oxalis species are influenced by both the onset and quantity of winter rainfall and the average daily temperatures (Dreyer et al., 2006). In drier years, less seed production due to reduced flowering could be compensated for by vegetative reproduction via bulbil (Salter, 1944). The ability of bulbs and bulbils to persist and multiply over many seasons offers 
the southern African members of Oxalis a very effective means of vegetative reproduction. Although the means of vegetative bulb/bulbil dispersal is still understudied, field observations have shown that most young bulbils establish very close to the parent plant to form clonal clumps in most species. Over the longer term such high levels of clonality would reduce genetic diversity and fecundity. Ellstrand and Antonovics (1985) showed that populations of asexually derived individuals had lower survivorship and fecundity than populations of sexually derived individuals.

Although the levels of clonal growth are very variable within and between Oxalis species, most rare species displayed moderate levels of clonality, while 0 . giftbergensis showed very low levels of clonality. This suggests that sexual reproduction is efficient and adequate in 0 . giftbergensis, with no current dependence on clonal propagation for survival. Should conditions for seed production become unfavourable though, the levels of clonality may increase. This seems to have occurred in O. natans (1), which is currently experiencing unfavourable conditions for sexual reproduction.

\subsection{Ecology}

Many of the rare species have very specific habitat requirements (e.g. O. amblyosepala, O. comptonii, O. oculifera, O. oreophila and $O$. hygrophila), which confine them to small, isolated populations within specific habitats. They are unable to increase their population sizes due to the unavailability of suitable habitat, which renders them extremely threatened by future habitat loss (Pilgrim et al., 2004). Other species, e.g. O. giftbergensis and $O$. natans, may have been widely distributed before, but are now restricted to habitat relicts. Climate change predictions of a $0.5-1.0^{\circ} \mathrm{C}$ increase in temperature and $25 \%$ decrease in annual rainfall is predicted for the CFR in the next 50 years (Rutherford et al., 1999), which should have a dramatic impact on the Cape flora, especially the rare species (Bond, 1997; Hannah et al., 2002; Oostermeijer, 2003). It poses a major threat to Oxalis species confined to seasonally waterlogged or aquatic habitats. The potentially severe negative impacts of climate change on such species are already observed in $\mathrm{O}$. hygrophila, a species restricted to waterlogged seepage bands, of which no plants were observed during the drier 2005 or 2006. The persistent absence of this species from its type and only known locality over the past number of years now raises fears that it may, in fact, have become extinct. The Giftberg endemics confined to seasonally waterlogged habitats also varied in meta-population number and size along with the variable rainfall patterns observed over the study period.

\section{Conclusions}

Tristyly expression is variable among the Oxalis species studied, to the extent that very view generalizations can be made about its effect on rarity and/or the effect of rarity on this breeding system. The reproductive success of two populations (O. amblyosepala and O. natans (1)) appears to be limited by tristyly, but in $O$. natans (1) reduced reproductive success could also result from low fecundity in small/disturbed populations. The reproductive success of $O$. natans (2), O. giftbergen- sis and 0 . oreophila is unaffected by tristyly and these species appear not to be under immediate threat provided that their habitats are preserved. Other populations overcome possible limitations to sexual reproduction by shifts in the self-incompatibility component of tristyly (O. comptonii and O. oculifera), while still retaining the potential to out-cross if chance cross-pollinations are possible.

Most of the rare species are limited by their specific habitat requirements. Species confined to seasonally waterlogged habitats are of urgent concern in view of the proposed implications of climate change and the observed reproductive variability of such species under variable rainfall patterns.

\section{Acknowledgements}

We thank the South African National Biodiversity Institute (Threatened Species Program) and the National Research Foundation (GUN 2053585) for funding this project. In addition, we acknowledge the South African Weather Service and Mr. Chris de Jong for rainfall data and the Western and Northern Cape Nature Conservation boards for issuing the required permits.

\section{R E F E R E N C E S}

Barrett, S.C.H., 1979. The evolutionary breakdown of tristyly in Eichhornia crassipes (Mart.) Solms (water hyacinth). Evolution 33, 499-510.

Barrett, S.C.H., 1985. Floral trimorphism and monomorphism in continental and island populations of Eichhornia paniculata (Spreng.) Solms. (Pontederiaceae). Botanical Journal of the Linnean Society 25, 41-60.

Barrett, S.C.H., 1992. Heterostylous genetic polymorphisms: model systems for evolutionary analysis. In: Barrett, S.C.H. (Ed.), . In: Evolution and Function of Heterostyly, Monographs on Theoretical and Applied Genetics, vol. 15. Springer-Verlag, Berlin, pp. 1-29.

Bond, W.J., 1997. Functional types for predicting changes in biodiversity: a case study in Cape Fynbos. In: Smith, T.M., Shugart, H.H., Woodward, F.I. (Eds.), Plant Functional Types: Their Relevance to Ecosystem Properties and Global Change. Cambridge University Press, Cambridge, pp. 174-194.

Brys, R., Jacquemyn, H., Endels, P., Van Rossum, F., Hermy, M., Triest, L., De Bruyn, L., Blust, G.D.E., 2004. Reduced reproductive success in small populations of the selfincompatible Primula vulgaris. Journal of Ecology 92, 5-14.

Burne, H.M., Yates, C.J., Ladd, P.G., 2003. Comparative population structure and reproductive biology of the critically endangered shrub Grevillea althoferorum and two closely related more common congeners. Biological Conservation 114, 53-65.

Byers, D.L., 1995. Pollen quantity and quality as explanations for low seed set in small populations exemplified by Eupatorium (Asteraceae). American Journal of Botany 82, 1000-1006.

Byers, D.L., Meagher, T.R., 1992. Mate availability in small populations of plant species with homomorphic sporophytic self-incompatibility. Heredity 68, 353-359.

Charlesworth, D., 1979. The evolution and breakdown of tristyly. Evolution 33, 486-498.

Dreyer, L.L., Esler, K.J., Zietsman, J., 2006. Flowering phenology of South African Oxalis - possible indicator of climate change? South African Journal of Botany 72, 150-156. 
Eckert, C.G., Barrett, S.C.H., 1992. Stochastic loss of style morphs from populations of tristylous Lythrum salicaria and Decodon verticillatus (Lythraceae). Evolution 46, 1014-1029.

Ellstrand, N.C., Antonovics, J., 1985. Experimental studied on the evolutionary significance of sexual reproduction. II. A test of the density-dependent selection hypothesis. Evolution 39, 657-666.

Franceschinelli, E.V., Bawa, K.S., 2000. The effect of ecological factors on the mating system of a South American shrub species (Helicteres brevispira). Heredity 84, 116-123.

Goldblatt, P., Manning, J., 2000. Cape Plants: A Conspectus of the Cape Flora of South Africa. Strelitzia, vol. 9. National Botanical Institute, Pretoria, South Africa, pp. 12-13.

Graham, S.W., Barrett, S.C.H., 2004. Phylogenetic reconstruction of the evolution of stylar polymorphisms in Narcissus (Amaryllidaceae). American Journal of Botany 91, 1007-1021.

Hannah, L., Midgley, G.F., Lovejoy, T., Bond, W.J., Bush, M., Lovett, J.C., Scott, D., Woodward, F.I., 2002. Conservation of biodiversity in a changing climate. Conservation Biology 16, 264-268.

Hilton-Taylor, C., 1996. Red Data List of Southern African Plants. Strelitzia, vol. 4. National Botanical Institute, Pretoria, South Africa.

Hooftman, D.A.P., van Kleunen, M., Diemer, M., 2003. Effects of habitat fragmentation on the fitness of two common wetland species, Carex davalliana and Succisa pratensis. Oecologia 134, 350-359.

Jankowski, J.E., Rabenold, K.N., 2007. Endemism and local rarity in birds of neotropical montane rainforest. Conservation Biology $38,453-463$.

Kumwenda, M., Dreyer, L.L., Marais, E.M., 2004. A taxonomic reassessment of the varieties of Oxalis minuta (Oxalidaceae) and the change of $O$. minuta var. callosa to specific rank as $O$. hygrophila. South African Journal of Botany 70, 259-264.

Lourteig, A., 1994. Oxalis L. subgénero Thamnoxys (Endl.) Reiche emend. Lourteig. Bradea, Boletim do Herbarium Bradeanum 7 1-199.

Lourteig, A., 1995. Oxalis L. subgenus Trifidus Lourt. subgen. nov.. Bradea 6, 389-392.

Lourteig, A., 2000. Oxalis L. subgénero Monoxalis (Small) Lourteig, Oxalis y Trifidus Lourteig. Bradea 7, 201-629.

Luijten, S.H., Dierick, A., Gerard, J., Oostermeijer, B., Raijmann, L.E.L., Den Nijs, H.C.M., 2000. Population size, genetic variation, and reproductive success in a rapidly declining, selfincompatible perennial (Arnica montana) in the Netherlands. Conservation Biology 14, 1776-1787.

Myers, N., Mittelmeier, R.A., Mittelmeier, C.G., da Fonseca, G.A.B., Kent, J., 2000. Biodiversity hotspots for conservation priorities. Nature 403, 853-858.

Oberlander, K.C., Dreyer, L.L., Bellstedt, D.U., Reeves, G., 2004. Systematic relationships in southern African Oxalis L.
(Oxalidaceae): congruence between palynological and plastid trnL-F evidence. Taxon 53, 977-985.

Oostermeijer, J.G.B., 2003. Threats to rare plant persistence. In: Brigham, A.C., Schwartz, M.W. (Eds.), Population Viability in Plants, Conservation, Management, and Modeling of Rare Plants. Springer, Berlin, pp. 17-58.

Ornduff, R., 1964. The breeding system of Oxalis suksdorfii. American Journal of Botany 51, 307-314.

Ornduff, R., 1972. The breakdown of trimorphic incompatibility in Oxalis section Corniculatae. Evolution 26, 52-65.

Ornduff, R., 1974. Heterostyly in South African flowering plants: A conspectus. Journal of South African Botany 40, 169-187.

Pärtel, M., Kalamees, R., Reier, Ü., Tuvi, E.L., Roosaluste, E., Vellak, A., Zobel, M., 2005. Grouping and prioritization of vascular plant species for conservation: combining natural rarity and management need. Biological Conservation 123, 271-278.

Pilgrim, E.S., Crawley, M.J., Dolphin, K., 2004. Patterns of rarity in the native British flora. Biological Conservation 120, 161-170.

Primack, R.B., 1993. Vulnerability to extinction. Essentials of conservation biology. Sinnauer Associates Inc., Sunderland, USA.

Pullin, A.S., 2002. Conservation Biology. Cambridge University Press, Cambridge.

Richards, J.H., Barrett, S.C.H., 1992. The development of heterostyly. In: Barrett, S.C.H. (Ed.), Evolution and Function of Heterostyly, Monographs on Theoretical and Applied Genetics, vol. 15. Springer-Verlag, Berlin, pp. 85-127.

Rutherford, M.C., Midgley, G.F., Bond, W.J., Powrie, L.W., Roberts, R., Allsopp, J., 1999. South African country study on climate change: plant biodiversity, vulnerability and adaptation assessment. Final Report. US Country Study on Climate Change.

Salter, T.M., 1944. The genus Oxalis in South Africa. A taxonomic revision. Journal of South African Botany (Suppl.1), 1-355.

Sokal, R.R., Rohlf, F.J., 1995. Biometry: The Principle and Practice of Statistics in Biological Research. W.H. Freemann and Company, New York.

Van Rossum, F., De Sousa, S.C., Triest, L., 2004. Genetic consequences of habitat fragmentation in an agricultural landscape on the common Primula veris, and comparisons with its common rare congener, $P$. vulgaris. Conservation Genetics 5, 231-245.

Weller, S.G., 1976. Breeding system polymorphisms in a heterostylous species. Evolution 30, 442-454.

Weller, S.G., 1992. Evolutionary modifications of tristylous breeding systems. In: Barrett, S.C.H. (Ed.), Evolution and Function of Heterostyly, Monographs on Theoretical and Applied Genetics, vol. 15. Springer-Verlag, Berlin, pp. 247-271.

Zapata, T.R., Arroyo, M.T.K., 1978. Plants reproductive ecology of a secondary deciduous tropical forest in venezuela. Biotropica $10,221-230$ 